\title{
Co-creating sustainable urban metabolism towards healthier cities
}

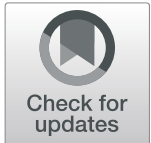

\author{
Isabel Fróes ${ }^{1 *}$ (D) and Malene Køster Lasthein ${ }^{2}$
}

\author{
* Correspondence: ifr.msc@cbs.dk \\ ${ }^{1}$ Department of Management \\ Society and Communication, \\ Copenhagen Business School, \\ Dalgas Have 15, 2000 Frederiksberg, \\ Denmark \\ Full list of author information is \\ available at the end of the article
}

\begin{abstract}
In this article, we initially present and discuss the existing concepts covering sustainable and healthy cities, and urban metabolism infrastructure. The urban metabolism infrastructure distributes a wide range of key resources to citizens through various modes of transportation. Although the technical infrastructure and people in cities tend to be perceived as separate systems, they need to be acknowledged as co-dependent. Thus, co-creating urban metabolism and its infrastructure should be an integral part of developing a healthy city. We use mobility and transportation examples from the Cities-4-People project as a case to discuss the role of citizens and local stakeholders in co-creating solutions to improve their cities' mobility through the urban metabolism and sustainability lens.

Furthermore, we discuss the project process outcomes, leading to a set of guidelines towards achieving healthier cities.

Keywords: Urban metabolism, Healthy city, Urban infrastructure, Co-creation, Sustainable city, Urban prototyping
\end{abstract}

\section{Science highlights section}

- To develop healthier cities requires an understanding of the ever changing citizens' needs and how their choices impact the local urban metabolism.

- Co-production and co-creation of urban solutions with local citizens and other stakeholders contribute to a wider awareness of the city as an inter-dependent metabolism as a possible approach to achieve the WHO healthy city parameters.

- Authorities need to tangibly experience results emerging from bottom up approaches to understand its real value and possible impact.

\section{Policy and practice recommendations}

- Include urban prototypes in the planning of all urban development budgets.

- Educate authorities on the economical, social and environmental value of including citizens' participation as an intrinsic part of any city planning process.

(c) The Author(s). 2020 Open Access This article is licensed under a Creative Commons Attribution 4.0 International License, which permits use, sharing, adaptation, distribution and reproduction in any medium or format, as long as you give appropriate credit to the original author(s) and the source, provide a link to the Creative Commons licence, and indicate if changes were made. The images or other third party material in this article are included in the article's Creative Commons licence, unless indicated otherwise in a credit line to the material. If material is not included in the article's Creative Commons licence and your intended use is not permitted by statutory regulation or exceeds the permitted use, you will need to obtain permission directly from the copyright holder. To view a copy of this licence, visit http://creativecommons.org/licenses/by/4.0/. 
- Create spaces, such as city labs, for interacting and educating citizens about their demands of resources' and how they impact the overall city flow of goods and transport.

\section{Introduction}

Cities are ecosystems based on a socio-technical system, which includes physical systems with infrastructure and buildings and a human system of people, movement and activity (Hillier 2009). The technical and human systems are completely intertwined and co-dependent, as they influence and affect as well as transform and maintain each other.

The (mostly) increasing urban population (United Nations, Department of Economic and Social Affairs, P. D 2019) pushes the demand for goods and resources in cities and the need for infrastructure to uphold the demand. Simultaneously, cities must offer green spaces and activities to its citizens. However, how do these divergent aspects coexist and what is the role of people in shaping a healthy urban metabolism (Baccini 1997; Kennedy et al. 2007; Rashed 2018; Thomson and Newman 2018b)?

In this paper, we suggest that a healthy city is a city that understands and works with this complex interdependency of actors, acknowledging and dedicating resources to keep a steady vigorous flow of its metabolism. Furthermore, we propose that cities can achieve a healthier metabolism and thus develop better flows, through applying cocreation tools and methodologies that include the various city's stakeholders. We illustrate this approach focusing on a case of co-creating mobility and transportation solutions from the Cities-4-People (C4P) project. Co-creation is to be understood as 'the process of creating new public policies and services with people and not for them' (European Commission 2016). Building on co-creation, we summarize the concept of co-production (Alford 2014; Cassia and Magno 2009; Sorrentino et al. 2018) as the process of engaging various stakeholders in conceptualising and testing solutions before they are implemented in urban areas.

In this article, we set out to present how cities' metabolisms can become more sustainable and healthier through inclusive processes, co-created with a range of citizens and other local stakeholders, impacting infrastructure that contributes positively to creating cities where people thrive.

We guide our discussion through the following research questions:

- How can current urban infrastructure be a part of creating sustainable and healthy cities for people?

- How can co-creation methods lead to novel development processes that inform and influence the cities' urban metabolism and infrastructural patterns?

- What types of recommendations are required to help cities achieve a 'healthy city' status (Healthy Cities Vision 2019)?

We present the concept of healthy cities followed by those covering urban metabolism and its infrastructure to understand what these concepts entail in diverse contexts. Thereafter, we introduce the Cities-4-People project, followed by a discussion of the initially presented concepts intertwined with the project methods and preliminary 
results. Lastly, we suggest guidelines informing how citizens can play an active role in co-developing and being key players in co-creating the future of their healthy cities.

\section{Sustainable and healthy cities}

Cities are responsible for contributing up to $80 \%$ of all greenhouse gas emissions (Siri 2016), and for the past many years it has been consistent that urbanisation meant increasing economic growth and increasing emission of greenhouse gases (World Bank 2010). By 2050 it is expected that close to $70 \%$ of the world's population live in urban areas, compared to 54\% in 2014 (United Nations (UN) 2018). For these reasons, it is urgent for cities to be able to change their current processes to develop sustainable cities, where economic growth is decoupled from finite resource consumption.

Along with the publication of the report 'Our Common Future' (Brundtland 1987), it became commonly accepted that sustainable development is a "development that meets the needs of the present without compromising the ability of future generations to meet their own needs" (ibid.) and that future developments need to align with this approach. This definition was later expanded to encompass the triple bottom line, a development that not only proves economically beneficial but equally benefits social and environmental aspects. Both notions of sustainable development and triple bottom line are present in the definition of a sustainable city, defined as 'an urban community committed to improving the well-being of its current and future residents, while integrating economic, environmental, and social considerations' (World Bank 2010, p. 1).

Well-being has been indicated as a key aspect within sustainability (Rogers et al. 2012) and although the term health for many people is associated with hospitals and doctors (Hancock and Duhl 1986), this term is also applicable and connected to city development (Rogers et al. 2012). An attempt to transfer the ideas of medical health onto health for people in cities makes one think of access to clean air, non-chemically infested goods, spaces to move, exercise and socialise with other people, areas to have gatherings, intimate meetings and sports activities. In other words, bringing in the notions of health in city development involves many different disciplines and requires cross-disciplinary, cross-institutional and cross-academic collaboration with distinct expertise from urban planners, economists, anthropologists, architects, etc., who might each propose different perspectives on what a healthy city is (ibid.). Whereas most cities in the twentieth century have been planned to accommodate a range of vehicles, people's health would benefit from having more options for walking or biking. By adopting these health-friendly options, citizens have an impact reducing the number of cars on their roads, decreasing greenhouse gas' emissions, thus helping mitigate air pollution. Through this angle, the concepts dealing with health and sustainable development in cities are direct and clearly intertwined (Siri 2016). Aligning with this perspective, the World Health Organization (WHO) has brought forward a vision of a healthy city as:

"Healthy cities are places that deliver for people and the planet. They engage the whole of society, encouraging the participation of all communities in the pursuit of peace and prosperity. Healthy cities lead by example in order to achieve change for the better, tackling inequalities and promoting good governance and leadership for health and well-being. Innovation, knowledge sharing and health diplomacy are valued and nurtured in healthy cities" (Healthy Cities Vision 2019). 
During the WHO Healthy Cities Project, eleven parameters were suggested by Hancock and Duhl to form a Healthy City (de Leeuw 2012; Hancock and Duhl 1986) as shown in Table 1:

What is present throughout all the parameters is that they pose different aspects of creating cities, although they do not indicate how these parameters can be achieved, and only one of them indicates the importance of citizens having a voice in shaping a healthy city.

Designing healthy cities requires a thorough and wide understanding of the requirements and demands from citizens. However, not only must the citizens be accounted for, it is just as important to be able to extract the side effects of choices. For example, planning cities for cars might be a convenient choice for some citizens, however it reduces the ease of moving around on foot or by bike, leading to environmental degradation, obese citizens and other health risks as possible side effects (Barton and Grant 2013; Grant et al. 2017). Therefore, citizens themselves, working closely together with urban planners, service designers, politicians, and other key stakeholders have an important role to play in designing their cities. This approach could also have a transformative impact in disadvantaged areas, often overlooked in city planning due to their social and economic profile, consequently portrayed as a low real-estate investment and pushed to sideline projects. A healthy city should be healthy for all its citizens. Without acknowledging aspects of inclusiveness (or lack of) in city development and systematically planning how to reach and achieve inclusive processes, cities might fail to address key social inequalities that consequently will affect their overall liveability and health. To succeed on inclusive goals, cities require having a thorough overview of their metabolism, as to develop adaptable infrastructure feeding the ever-changing needs of their citizens of all backgrounds.

\section{Urban metabolism and its urban infrastructure}

Taking a closer look at sustainable cities ultimately leads to an insight of the needs and requirements of its citizens. To accommodate these needs, cities are currently consuming up to $80 \%$ of all resources (Baccini 1997; Girardet 2010). As one of the roles of the city is to facilitate the distribution of resources, city systems needs a solid infrastructure to handle materials, goods and energy often transported from afar, and import these into the city, where they are transformed, consumed and discarded to become litter. The system responsible for the flow of goods and energy for production, consumption

Table 1 Eleven parameters of a Healthy City by Hancock and Duhl (1986)

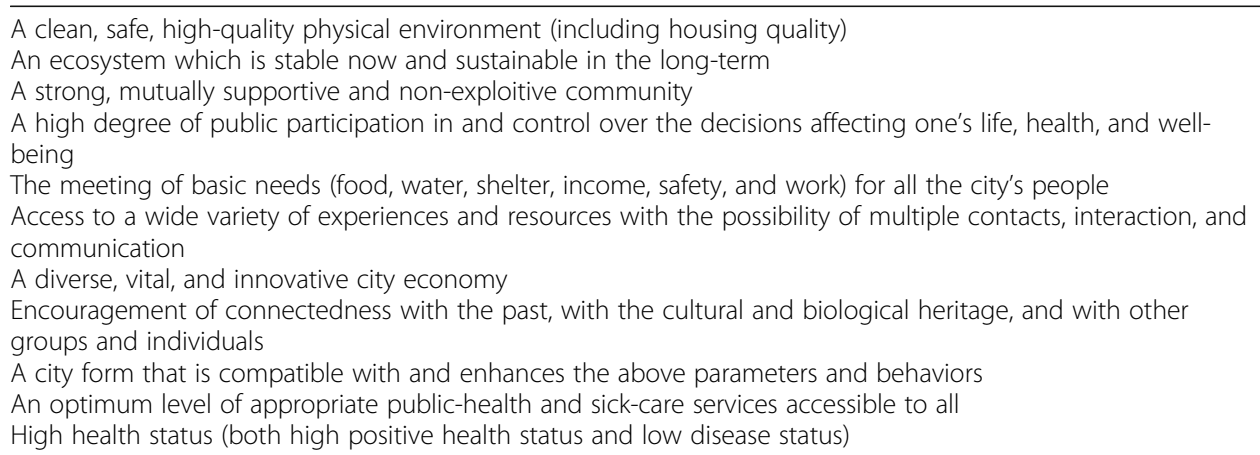


and waste management is called the urban metabolism (Baccini 1997; Dijst et al. 2018; Rashed 2018), defined as "the sum total of the technical and socio-economic processes that occur in cities, resulting in growth, production of energy, and elimination of waste" (Kennedy et al. 2007).

As the name implies, an urban metabolism requires a healthy digestion of resources and, as such, a steady flow of these resources and connectivity to reach citizens. The urban metabolism not only accounts for the technical and material infrastructure for distribution of goods but should also consider the human interactions taking place in order for them to flow. Today's citizens are reliant on large and continuous access to various types of resources, but, in its majority, they are unconcerned about the consequences of their own use of such means. Therefore, for the cities to transform into sustainable entities, citizens must understand how they are dependent on scarce natural resources (Girardet 2010) and have an active role to play in the future of sustainable development. Being aware of the city's own system and metabolism gives the citizens the power and possibilities to transform their own city and within this, their own urban metabolism. Although the urban metabolism has been investigated through analysis such as Material Flux Analysis (Baccini 1997; Dijst et al. 2018) and urban fabric composition (Thomson and Newman 2018b), we suggest the perspective that the urban metabolism is created and maintained solely as a consequence of and through human intervention. The various stakeholders in a city need to supply citizens with physical spaces for them to partake in continuous conversation with the development of the built environment (Mersal Mahmoud 2018). Therefore, the infrastructure of the metabolism or rather the built environment has the responsibility of not only distributing and facilitating material flows but just as decisively in shaping the cities for its people.

The urban infrastructure is the underlying grid supporting the urban metabolism and making the mobilisation of people and resources possible. The urban infrastructure consists of physical structures such as roads, railways, airports, bike paths, pavements, sewages, electrical cables, etc. Within the physical structures, heating, electricity, water, goods and people are transported and distributed around and, in and out of the urban sphere. The urban infrastructure applies massive pressure on the use and need of natural resources, and transport on its own is responsible for $13 \%$ of the global greenhouse gas emissions (UN-Habitat 2011).

Sustainable transformation of infrastructure in cities is necessary to change the current trend of rising greenhouse gas emissions. The urban infrastructure is comprised of volume, budget and timelines, all in large scales. Its complexity can seem daunting to local citizens, however both infrastructure and citizens are closely connected and mutually dependent. Transforming cities and urban infrastructure through local stakeholder co-creation processes have been described through concepts such as Urban Living Labs (Puerari et al. 2018; Späth and Knieling 2020), Urban Transition Labs (Nevens et al. 2013) and Learning Alliance (van der Jagt et al. 2019). Co-creating with multiple stakeholders have shown key benefits, e.g. increased ownership, engagement, strengthening social inclusivity, fostering creative and innovative ideas, etc. (Corsín Jiménez 2014; Khan et al. 2017; Puerari et al. 2018). In this aspect, the role of the urban infrastructure is both to facilitate the steady flow of resources through the urban metabolism and at the same time to uphold to the standard of healthy cities for the citizens. 
We suggest that the creation of healthy cities requires a well-functioning technical urban metabolism and urban infrastructure, which ultimately is the result of human activity and design. The relevance of inclusive co-creation tools and methods and a coproduction approach (Brandsen and Pestoff 2006; Bryson et al. 2017) in overall urbanplanning can help this process. Without the technical infrastructure of an urban metabolism that adapts to the ever-changing needs and demands of their citizens, goods and utility supplies could not be distributed efficiently, thus having a wider impact on the cities' health.

\section{Developing healthier cities through better mobility and transportation in the Cities-4-people project}

We choose to illustrate how to achieve a better urban metabolism and a healthier city through the Cities-4-People project, which focuses on new approaches for communitydriven sustainable mobility innovations at neighbourhood and urban district level. The project is briefly described in this section, followed by its methodology and preliminary results.

According to the World Health Organisation, 'people from multiple disciplines can effectively work towards creating healthy, sustainable and economically vital cities Healthy Cities' (Health Organization Regional Office for Europe, W 2014). One suggestion for achieving this goal through transformation of urban infrastructure could be changing the modes of transportation and thereby increase liveability for the citizens by changing their means and supply of mobility from private car usage to walking, biking and public transportation (Thomson and Newman 2018a, 2018b). This is the exact premise of the Cities-4-People project, where five urban areas have engaged a range of stakeholders, more precisely industry, academia, governance and citizens forming the quadruple helix (Curley and Salmelin 2008), to challenge top-down approaches to transport and mobility by creating a dynamic and inclusive bottom-up process approach. These four stakeholder groups have worked together towards various interventions tackling some of the cities' key mobility problems, identified earlier in the project process through qualitative and quantitative research. This setup informs the People Oriented Transport and Mobility (POTM) approach, with the understanding that citizens, who are making use of transportation and mobility resources, should have a voice in current and future mobility planning and development. In this project, urban mobility and transportation has followed the European Commission's goal, understood as 'the use of all the various modes of transport and organising "co-modality" between the different modes of collective transport (train, tram, metro, bus, taxi) and the different modes of individual transport (car, motorcycle, cycle, walking)'(European Commission 2007). The Cities-4-People project focus on these elements in the five distinct locations of Istanbul (Turkey), Trikala (Greece), Hamburg (Germany), Oxfordshire (United Kingdom) and Budapest (Hungary). These cities are examples of diverse urban areas in terms of size, geography, population density and socioeconomic realities (Table 2), offering contextual and cultural differences to apply, test and validate the methodology.

The various ways people move around in their cities is currently determined by the different types of access and modes of transport available. Despite this unique co-dependence, citizens are not always involved in the decision-making processes 
Table 2 Cities-4-People cities average population

\begin{tabular}{|c|c|c|c|c|c|}
\hline \multirow[t]{2}{*}{ Aspects } & \multicolumn{5}{|l|}{ Locations } \\
\hline & Oxfordshire & Budapest & Trikala & $\begin{array}{l}\text { District of Üsküdar } \\
\text { (Istanbul) }\end{array}$ & Altona (Hamburg) \\
\hline Demographics & $161 \mathrm{~K}$ & 1.7 million & $62 \mathrm{~K}$ & $500 \mathrm{~K}$ & $262 \mathrm{~K}$ \\
\hline $\begin{array}{l}\text { Geographical } \\
\text { aspects }\end{array}$ & $\begin{array}{l}\text { Flat, inland. Large } \\
\text { residential } \\
\text { areas spread } \\
\text { across the } \\
\text { outskirts. } \\
\text { Centre is key } \\
\text { commercial } \\
\text { and business area. } \\
\text { Access to city } \\
\text { centre is key to } \\
\text { residents. }\end{array}$ & $\begin{array}{l}\text { Hilly and inland. } \\
\text { The city is divided } \\
\text { by the Danube } \\
\text { river. Businesses } \\
\text { and shopping } \\
\text { areas spread } \\
\text { across, intertwined } \\
\text { with residential } \\
\text { areas. }\end{array}$ & $\begin{array}{l}\text { Flat and } \\
\text { inland. } \\
\text { Central } \\
\text { business } \\
\text { area, } \\
\text { residential } \\
\text { area spread } \\
\text { across the } \\
\text { city. }\end{array}$ & $\begin{array}{l}\text { Hilly and coastal. } \\
\text { Businesses and } \\
\text { shopping areas } \\
\text { spread across, } \\
\text { intertwined with } \\
\text { residential areas. } \\
\text { Access to other } \\
\text { areas in Istanbul } \\
\text { is key to its } \\
\text { residents. }\end{array}$ & $\begin{array}{l}\text { Flat and inland. } \\
\text { Central business } \\
\text { area, residential } \\
\text { area spread across } \\
\text { the neighbourhood. } \\
\text { Access to central } \\
\text { Hamburg is key to } \\
\text { residents. }\end{array}$ \\
\hline
\end{tabular}

of city development. Therefore, this three-year project has focused on precisely this key involvement aspect, bringing together key stakeholders to research, co-create and co-decide how citizens can improve and impact how people and goods move in their cities.

The Cities-4-People project makes use of a mixed-method methodological approach and started with a qualitative and quantitative research, investigating what citizens' views and experiences of mobility and transportation were in the five project cities. The combination of a qualitative and quantitative methodology was extremely useful in mapping and understanding contradictions and relationships between quantitative results and qualitative findings. This approach has ensured that the study's findings were strongly rooted in citizens' experiences.

The project has had a clear process with distinct phases, described as development, pilot, scale-up and evaluation in the project proposal. These phases intersected to create a dynamic flow. To better illustrate the actual process within each of the phases, they have been broken down in Table 3 to aid with a clearer and more detailed overview of the project process.

In order to run this process, the project partners have set up in each of their locations a Mobility Lab (C4P Mobility Labs | Cities4People n.d.). These Labs are both 'static' (based in one location) and mobile (stands and moveable vehicles), based on local contexts' needs. The Labs have been used as a meeting point and an open invitation to local citizens to learn and get involved in the project. They also serve as hosting spaces for some of the workshops and project events. The labs offer a setting where diverse tools and a varied set of mobility and transportation information is available, where local communities can gather to discuss, debate and co-create. The reason behind having such a dedicated area grounds the idea of having a third space, or a dedicated space where people can participate without a pre-defined role. Having this space is key towards helping create a democratic and fair community engagement, as it breaks with pre-established hierarchies; instead, it levels the participants as members of a mobility community, who have complementary expertise.

During the initial months of the project (June-October 2017), online questionnaires and interviews were deployed, followed by an analysis period. The online questionnaires covered people's routes and modes of transportation and were distributed via 
Table 3 Suggested definitions for the Cities-4-People process phases

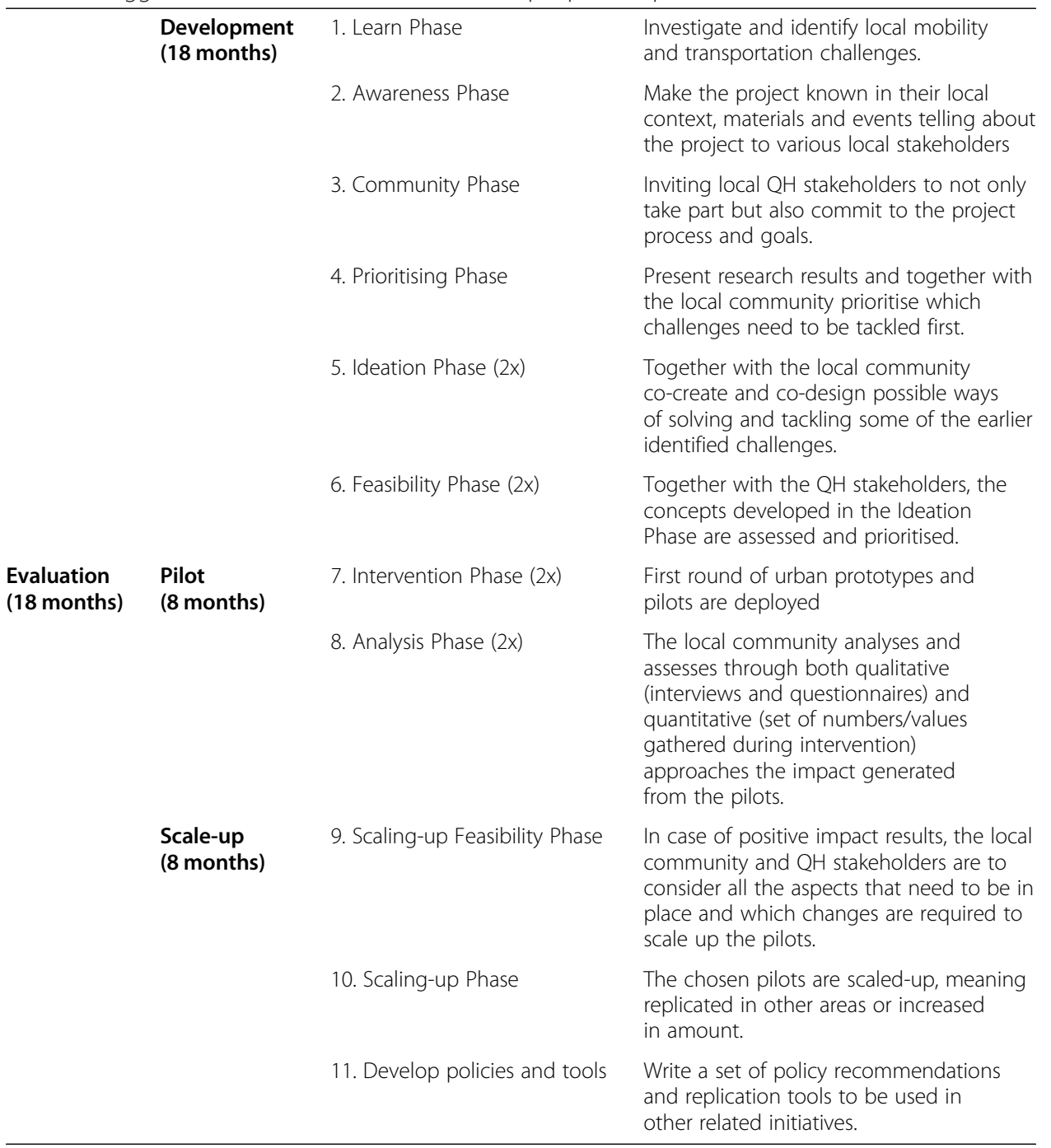

online platforms and newsletters. This data collection reached a high number of citizens, with 2550 respondents from all pilot locations. In order to better visualize how people moved in their cities, the project partners chose to use Maptionnaire (Maptionnaire n.d.), an online tool combining questionnaires and maps, where respondents can pinpoint routes, problems, etc. This tool has allowed each partnering location to visualize the existing heavy flows as well as city 'nodes', where flow is obstructed by adverse transportation and mobility challenges. Concomitantly with the online questionnaires, the local city partners conducted 75 semistructured interviews with 15 respondents per city belonging to the quadruple helix stakeholder group; transport authorities, local citizens, municipality representatives and academics. The questionnaires and interviews covered a wide range of aspects impacting mobility and transportation, such as:

- What characterised the travel patterns in the city?

- What were the key mobility challenges in the city? 
- Were the citizens satisfied with the current transportation system and mobility infrastructure?

- Did they make use of public places in the city?

- Were citizens satisfied with the policies of local or national governments concerning urban mobility in their city?

The research results have indicated a number of urban challenges and informed all the following events in the project process. ${ }^{1}$

As shown in Table 4, some of the aspects that affect city flow deal with heavy traffic congestion, as a result of private car usage, access to public transport information and limited schedules, as well as restricted infrastructure supporting alternative modes of transportation, such as biking and walking (broken or discontinued pavements, not enough signalization, blocked pavement by businesses, etc.).

With the data at hand, cities had tangible material to work with their local communities. Through workshops and regular conference calls focusing on training local partners from each city to learn and apply co-creation methods and tools, the local project partners have learned a set of activities to facilitate team building, ideation, conceptualising and voting processes. These activities have been combined in local mobility kits, ${ }^{2}$ and each of the local project representatives have adapted and applied the tools to their own contexts in many different project events.

The pilot cities completed ideation phases in their first year of the project. The local community joined project representatives to co-create intervention ideas and develop them into concepts, containing specific aspects and processes needed to be in place towards deploying such concepts. During the facilitated process, it became clear that the project had succeeded in creating local communities, committed to transforming their urban environments. As these communities are composed of different social groups (local authorities, transportation businesses, bike associations, elderly and young members, groups representing those with different types of impairments, neighbourhood residents), the discussions have been vibrant, informative and rich, and owing to the chosen set of tools, everyone has had a voice. These events also have served as a meeting point for discussions regarding the future of the cities that go beyond the project scope. Nevertheless, they are of extremely relevance towards urban planning and the cities' urban development plans.

Throughout these events, it has also become clear how citizens directly connect the way they move in their cities to their quality of life. From time to health perspectives, how they are able or unable to use certain modes of transport or reach destinations within a reasonable time, frames their daily routines. However, these same citizens also acknowledged that modern expected conveniences, delivery services, shared distribution and shared mobility are also intrinsic factors that might compose their everyday lives.

\section{Co-creating healthy urban metabolism infrastructure}

The Cities-4-People project context is the base for the re-assessment of the current urban metabolism (Baccini 1997; Kennedy et al. 2007; Rashed 2018; Thomson and

\footnotetext{
${ }^{1}$ The conceptual framework and full research results can be found at https://cities4people.eu/resources/c4preports/page/2/

${ }^{2}$ https://cities4people.eu/citizen-mobility-kit/
} 


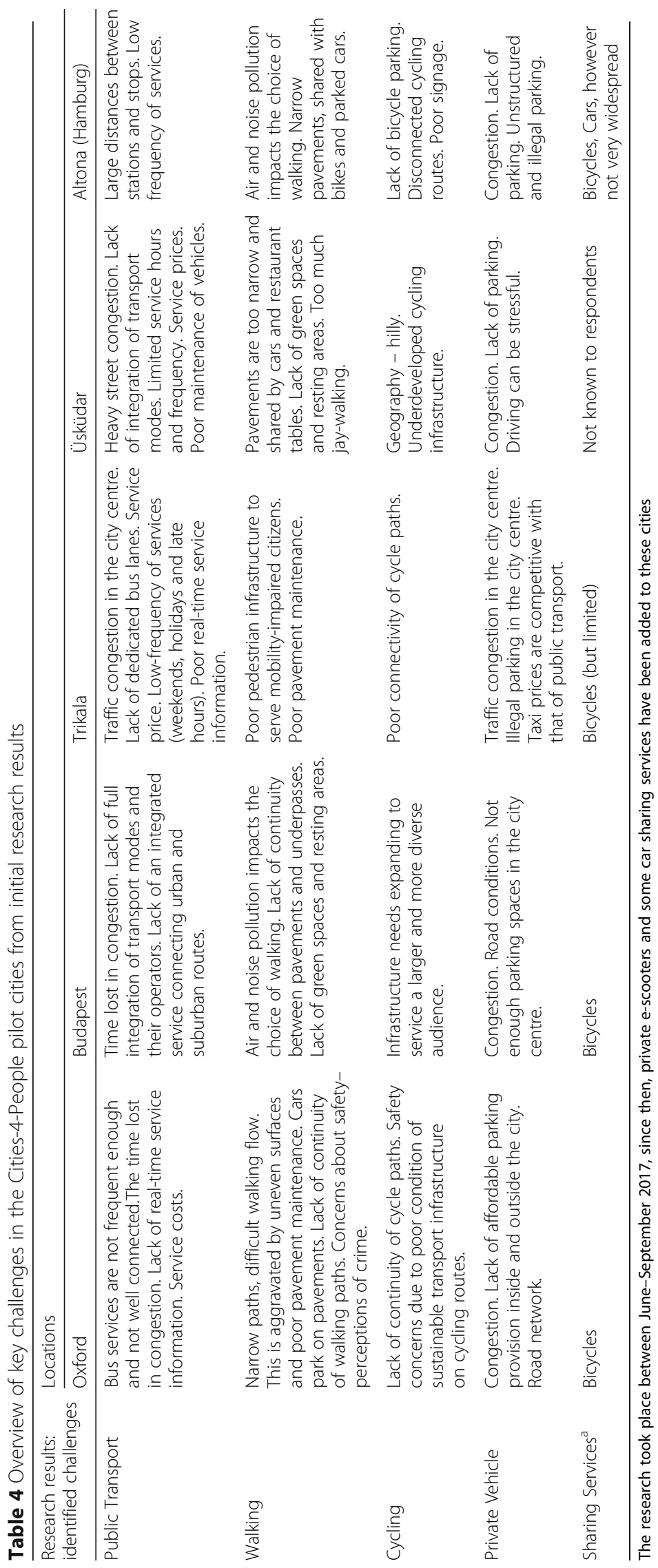


Newman 2018b) and healthy cities definitions (Duhl and Sanchez n.d.; Healthy Cities Vision 2018; World Health Organization (WHO) 2019). In the project, as challenges related to transport and mobility emerged, the preliminary results created a map of citizens' perceptions and needs when moving around their cities. These needs very much intertwine with how the city might and could develop, and it aligns with basic requirements of sustainable development.

The project preliminary results (Table 4) qualified themselves as key issues in how citizens rated their quality of living and daily mobility challenges. Acknowledging and facing these challenges raised a number of questions, emerging from discussions of the roles of citizens in determining or influencing the health of cities and their metabolisms, as mentioned earlier in our introduction. In the case of the Cities-4-People pilot cities, it has become clear that it is not possible to detach mobility from the healthy city perspective. The city infrastructure cannot be detached from its citizens. They form, in conjunction, the vital functioning of the city. Citizens are the livelihood of the city infrastructure. Without them, there is no city. Therefore, providing the means and modes to co-create the city successfully is one of the aspects helping achieve a healthy city.

Modes of transportation and mobility play a key role in the city health and to create a cohesive metabolism, the city needs continuous planning for adaptation. The infrastructure, instead of only having the responsibility of being the most effective distributor of resources, should be able to partake in the development of healthy cities. The urban infrastructure and mobility should allow for changes, sustainable future trends and growth, and yet unforeseen needs. In the Cities-4-People project, there was an understanding, which emerged from both the research and the events' participants that there are clear mobility needs, e.g. getting from A to B for working, studying, meeting people, running errands, etc.. However, these needs are not necessarily linked to the modes of transport currently in use, but rather to expectations emerging from habit and convenience. Thus, how citizens feel and describe their use and access to transportation and mobility in their city need to be accounted for in a more inclusive manner. In order to achieve this goal, we advocate that cities need an adaptable infrastructure, where each city develops a framework for continuous inclusion and adaptation, where upcoming changes can be incorporated fast or even tried out with urban prototypes, without the need for large infrastructural investment. In the Cities-4-People project, cities have developed initial interventions deployed during the summer of 2019. Based on the interventions' results - all interventions were analysed and assessed by their stakeholders and other residents regarding impact, value, quality, etc. - one of them has been chosen to be scaled up and possibly expanded or replicated in another city area. ${ }^{3}$ However, more prominently, the project suggests the co-production (Bryson et al. 2017) process itself as a possible outcome. By incorporating a bottom-up, inclusive approach, creating possibilities for urban prototyping, cities can positively impact their future urban developments. Such processes could be aggregated into strategies towards creating and maintaining healthier cities and informing some of the policy recommendations to better guide cities growth.

${ }^{3}$ The scaled-up interventions ran from primo January until ultimo March 2020, however due to the pandemic, interventions were stalled early March. Therefore, results are not the final and the final evaluation analysis is to be resumed later in the year if an amendment is granted. 
Noteworthy, when citizens become aware of not only how they move in a city, but also grasp the larger picture, as how goods and services move in the cities to serve them, they acquire a wider perspective on mobility and transportation. For example, that the morning traffic congestion might not be caused only by people going to work, but also the delivery of goods. As a wide range of services becomes part of the life's convenience, they also join as contributors to pollution, noise, and traffic as they share the roads, biking and pavement spaces. Consequently, during the Cities-4-People project a large number of implementable concepts were generated, not only focusing on personal modes of transportation, but also on deliveries, storage, access, information, etc. All of these different aspects influence mobility in distinct ways.

The interventions ran from early March 2019 until end of September 2019, and the following aspects were temporarily implemented and tested in the pilot cities based on co-creation meetings and workshops' results:

Hamburg (Germany), district of Altona:

- Installed bicycle parking racks in some areas of the street that were before reserved for cars (adressing the lack of infrastructure for bikers).

- Tested new modes of delivery service with cargo bikes (addressing ways of tackling congestion).

- Hosted events that brought together transportation sharing services groups to inform citizens about the various sharing options available in their city (towards increasing the uptake in sharing services).

Oxfordshire (United Kingdom), Barton neighbourhood (chosen due to its population and scarce transport options):

- Created an information packet that includes information on how to access DRT, as well as to inform the local community about their active travel options around Oxfordshire.

- Partnered with a transport on-demand company and supermarkets to provide subsidised transport for residents to do grocery shopping.

- Delivered a training program where citizens inform other citizens about transport related smartphone apps and how to use them.

Trikala (Greece):

- Built storage lockers in the central square to avoid morning shopping congestion.

- Temporarily closed the central square to car traffic to improve pedestrian flow.

- Provided wheelchair scooter attachments for free rental at the central square.

Budapest (Hungary):

- Offered people new ways of public traveling through a Mobility Point located on the upper embankment of the Danube at St. Gellért Square to decrease car usage and congestion. 
- Temporarily closed the road to traffic to allow citizens to experience a car-free 1-3 $\mathrm{km}$ long river embankment in Buda.

- Signs and other materials (maps, unique gamification elements) were set up to communicate access points to the river and encourage people to use them.

Istanbul (Turkey), district of Üsküdar:

- Placed benches at strategically identified steep spots in the neighbourhood to provide residents and pedestrians with resting points to help citizens in their daily steep routes.

- Hosted an event where citizens and public officials experienced what it is like to travel through the area with a disability to increase awareness of authorities regarding infrastructural needs concerning various types of impairments.

- Hosted a number of events focusing on the use of public gardens to promote healthier routes and tackle unsafety perceptions towards facilitating better access to public transportation.

The range of these pilot actions illustrate how mobility and transportation issues transcended the original perception of how individuals go from A to B, expanding to encompass how goods, people and the means of transport merge to make the city flow. Thus, to tackle mobility, citizens and other local stakeholders must be actively involved in the process towards understanding and defining how urban spaces can further develop to accommodate emerging demands that highly impact their cities' metabolism. Furthermore, working with citizens to assess and transform their own cities brings novel and untapped opportunities for developing urban infrastructure, which can challenge and improve current modes of city governance (Späth and Knieling 2020).

\section{Healthier cities}

Natural resources and energy flow systems in cities are intrinsically linked to the people creating these demands (Baccini 1997; Thomson and Newman 2018b). However, citizens, while engaged in their own routines, might not necessarily be aware of their role in shaping urban metabolism and infrastructure. They might not feel it is in their capability to transform how they influence and are influenced by the use of these same resources. Like Cities-4-People, other projects have been addressing these aspects by prototyping ways for citizens to work together as active voices in urban development (Corsín Jiménez 2014). As an example, in areas that might have been neglected as a result of sudden business changes or de-industrialisation and, due to a low-cost opportunity, receive an influx of students, artists, etc. and transform themselves into highly desired 'hot spots'. This change in neighbourhood profile is followed occasionally by a real-estate rush, creating new investments and furthering developments in the area (Hristova et al. 2018; Rosenstein 2008). However, the wide range of resources required to fulfil the consequential emerging needs are not necessarily planned along with the local growth, and this change might lead to future problems, such as access and distribution. These problems represent a greater challenge than anticipated. They affect the lives of the local residents in various ways as well as impact the city health through creating nodes in the city system and congested flows of goods and people. With a larger 
number of residents and not enough access to cheap and frequent modes of transport, private car usage becomes high, leading to road congestion (as accessible routes tend to be implemented at later stages), decrease of air quality, increase of noise pollution and time spent in commuting. A pertinent example of a related issue affecting cities deals with neglected or struggling areas. Even in well-structured cities with a forwardthinking government, there are specific areas that struggle to thrive. Such cases might occur because of an infrastructural problem linked to poor mobility planning or lack of fast adaptation and upcoming needs of their residents. A possible strategy to address such urban infrastructure inequality, helping cities become healthier, could be to adopt a preventive approach, where city developments do not fall behind citizens' needs. Instead, the city would accompany existing flow changes, being able to foresee imminent issues. Existing knowledge of flows in cities could inform urban prototypes (Corsín Jiménez 2014; Thomson and Newman 2018b) as a way to temporarily test feasible solutions for future problems. It would require keeping up with current and future trends in city contexts, which could be done through a combination of city data, collected both through qualitative and quantitative approaches using smart (technology) solutions together with co-creation tools coming together in a city lab initiative. This preventive approach does not necessarily solve all infrastructural and mobility (of goods and people) challenges cities face. Nonetheless, it would allow for temporary spaces that could be populated in distinct ways, allowing for use, debates and assessment of a solution before it is permanently implemented. Using urban prototyping also provides a platform for education and nudging towards a desirable outcome. It can be in the form of temporary signs, passages and even ways of communicating recycling or better use of resources. The temporary aspect of an urban intervention provides enough data and can be exploited to a range of outcomes. From the perspective of the citizens and authorities, the interventions, despite their temporal aspect, facilitate an experience that can be transformative by providing enough knowledge to compare with a previous state, differentiating itself from what otherwise would only be described in texts or illustrations that are hard to 'feel' and not necessarily properly understood.

In one tangible example emerging from the Cities-4-People initiative and tackling this issue, in the district of Altona, Hamburg, citizens and local associations showed a high interest in regaining access to public spaces, currently dedicated to vehicles. Initially there was a suggestion to try to close a specific central area in Altona for vehicles for 1 month. As the municipality, transportation and other public authorities took part in some of the project's meetings, this idea was discussed and brought forward to the local district assembly, which voted to close the area of Ottensen for vehicles for 6 months (instead of one), starting in September 2019 (Cities-4-People n.d.). The six-monthperiod has provided enough data and time to assess the new role given to the chosen street, both its positive and challenging impacts. This closing of the street has sparked other routes and solutions, before latent thanks to previous street access, and set a possible frame for future urban design recommendations. These recommendations can include key requirements that need to be in place in order to carry out large scale urban prototypes (Corsín Jiménez 2014; Thomson and Newman 2018b) and valuable aspects that can help catalyse urban transition (Nevens et al. 2013).

Why is this relevant in the context of urban metabolisms? Such a change in the urban landscape can affect a number of valuable aspects in a city metabolism. When 
closing a street for cars, goods and other resources have to find novel models for distribution that are sustainable, efficient and compatible with the new regulations. Citizens also have to rethink routes, bringing life not only for the closed area but also to other areas yet to be explored. While this change might bring initial confusion and certainly some discomfort in the early days of the intervention, as citizens and other vehicles need to get out of their default routes and routines, it will provide enough data and local experience to assess its impact in the wider city perspective. With data at hand, an engaged society working along urban environments can redefine concepts of wellbeing and how to shape their urban environment. Thus, a healthier city is a city that understands and works with its complex interdependency of actors and infrastructure, acknowledging and dedicating resources to keep a steady vigorous flow of its metabolism. Only by offering citizens the chance to participate in urban transformations, gaining inside perspectives in how their everyday habits and routines impact the wider city metabolism, can cities create a more cohesive and sustainable development. Cities can learn how to best address some of their local issues, such as those impacting mobility, co-creating solutions based on a common and shared understanding of problems, using tools at hand.

In existing top-down governance approaches, which mostly shape how cities develop, citizens tend to participate only indirectly. Despite some responsibilities related to choosing the ones to govern through municipal and country elections, citizens tend to be fairly disconnected from learning more about local urban developments. This disconnection may impede residents to understand some of the sources feeding local challenges, such as those belonging to the urban metabolism infrastructure, and how they themselves might be impacted and have an impact in their everyday lives. The preliminary findings that emerged from the Research and Innovation action Project, Cities-4People have so far created a long-lasting transformation in all the five locations involved in the project, with some of the temporary interventions becoming permanent with high citizen approval, as in the case of Oxford and Istanbul ${ }^{4}$. The Mobility Labs equipped with co-creation methods and tools ${ }^{5}$ allowed for an aggregation of various citizens and other stakeholders, breaking with usual top-down governance approaches, positively disrupting the usual urban metabolism framework, and transforming local urban development experiences for the cities and citizens involved. The project process has offered the opportunity to embed citizens as one of the variables in the this framework, proving that through applying a more holistic approach to city development, cities can create more impactful solutions of higher public acceptance. Thus, we suggest that a healthier city needs to aggregate implementable processes through inclusive cocreation methods.

We argue that it is not enough to have parameters defining a healthy city. In order to achieve such parameters and goals, cities need guidelines. Therefore, we propose to contribute to the field of urban transformation by suggesting a few guidelines to help cities work towards achieving some of the WHO health city parameters. They are presented in Table 5.

\footnotetext{
${ }^{4}$ The other evaluations are still in process.

${ }^{5}$ https://ccn.waag.org/navigator/
} 
Table 5 Guidelines towards helping cities become a 'healthy city'

- The inclusion of co-creation and co-production through citizens' participation as an intrinsic part of any city planning process.

- Early deployment of temporary interventions (urban prototypes) towards assessing value and needs of areas in development.

- Creating spaces for interacting and educating citizens about their demands of resources' and impacts.

- Deployment of temporary products/services towards creating new citizen experiences and behaviours.

The health of a city needs to reflect not only the final result of citizens' health, but instead it needs to be healthy because the city functions in healthy ways, providing 'natural' flows towards better quality of life for both citizens and the resources they consume and produce.

Through co-creation labs, cities could have a space for learning and interaction by providing education on city development, consumption and waste of resources. These city labs' citizens can directly interact with key city planning strategies and suggestions for urban development. Furthermore, city labs should be located in areas highly frequented by residents, in order to be visible and accessible. Dedicating a space in the affected' or 'developing' urban area, where citizens and local associations can directly connect to local transport authorities and local governance, can provide a starting point towards ensuring an inclusive, open access approach towards urban development. However, this space needs to be perceived and used as a place where citizens and stakeholders from different groups and associations come together to be exposed to a range of perspectives, gaining insights into unique and general cases. By working together in such an environment, these groups face and collaborate with each other, avoiding classic setups with embeded hierarchical roles, instead providing nuances to common shared urban challenges.

\section{Conclusion}

This article proposes guidelines to achieving a healthier city, revisiting definitions of sustainable and healthy cities, urban metabolism, urban infrastructure, giving suggestions of how cities can approach urban development planning through the active inclusion of citizens and associations with co-creation processes. Furthermore, we suggest that urban metabolism definitions need to be expanded to encompass the flow of people to its original conceptualisation, being defined as the flow of people, goods and energy for production, consumption and waste management. The Cities-4-People project is used as a tangible case as it builds on existing definitions of urban metabolism and healthy cities by suggesting an even greater holistic approach. By inviting citizens to co-create, co-produce and shape the city structure and design, cities might be positively transformed through multiple solutions that can lead to more sustainable urban environments and better quality of living for their citizens (Hine and Mitchell 2001; Mollenkopf et al. 2005). The suggested guidelines to co-creating healthier cities are also a means to reach UN's Sustainable Development Goal n.11: Sustainable Cities and Communities. The methodology applied in the Cities-4-People project is one possible approach of how to engage local communities into a wider city planning. Additionally, this inclusive approach is a tangible way to develop what we identify as preventive urban medicine, providing an on-going and simultaneous 'care' in urban developments and possibly preventing future infrastructural problems. 
Our main contribution to urban transformations research lies in proposing a set of guidelines, grounded in the outcomes of the Cities-4-People project process, to help cities achieve their 'healthy city indicators', thus becoming healthier cities. Through the creation of community driven spaces in active urban contexts, distinct groups can come together to co-create and co-produce solutions through discussing, ideating and planning possible concepts that can be tested as urban prototypes, before being implemented long term (or disposed of in case of negative impact). This fast-paced and comprehensive process allows for a tangible creation and assessment of concepts, bringing forward learnings on a wide range of aspects, such as people and goods distribution routes, and health and economic impacts. The sense of commitment and ownership acquired by the community involved in the course of the project might also have an influence on the success of chosen solutions. As informed citizens, they understand the problems and reasons behind the changes, and they see the tested concepts as a positive process in their city. Moreover, informed citizens might be more prone to accept and engage in changes in the urban space that focus on more sustainable approaches and engage in political choices and decisions influencing policy recommendations towards building healthier cities for all.

Abbreviations

C4P: Cities-4-People project; QH: Quadruple Helix; POTM: People Oriented Transport and Mobility; WHO: World Health Organisation

\section{Acknowledgements}

The authors would like to thank all the project partners, the Department for Management, Society and

Communication at the Copenhagen Business School (CBS) and our colleagues, who provided valuable feedback towards this article. The authors thank the anonymous reviewers for their comments and suggestions made on earlier drafts of this paper. This article reflects only the authors' view, the European Agency is not responsible for any use that may be made of the information it contains.

\section{Authors' contributions}

IF has contributed mostly with the sections Developing healthier cities through better mobility and transportation in the Cities-4-people project, Co-creating healthy urban metabolism infrastructure, Healthier cities and conclusion. ML has mostly contributed with the Sustainable and healthy cities and Urban metabolism and its urban infrastructure sections. For the reviews, both authors have equally contributed to the whole article. The authors have read and approved the final manuscript.

Funding

The Cities-4-People project has received funding from the European Union's Horizon 2020 research and innovation programme under grant agreement No 723194

Availability of data and materials

The raw data is not available due to GDPR regulations, however all tools and up-to-date results from the C4P project can be found on reports available on the project website: cities4people.eu.

Ethics approval and consent to participate

Not applicable.

Consent for publication

Not applicable.

Competing interests

The author(s) declare(s) that they have no competing interests.

\section{Author details}

${ }^{1}$ Department of Management Society and Communication, Copenhagen Business School, Dalgas Have 15, 2000

Frederiksberg, Denmark. ${ }^{2}$ Circular Transition ApS, Bragesgade 10B Stuen, 2200 Copenhagen N, Denmark. 
Received: 1 May 2019 Accepted: 11 May 2020

Published online: 03 June 2020

\section{References}

Alford J. The multiple facets of co-production: building on the work of Elinor Ostrom. Public Manag Rev. 2014;16(3):299-316. https://doi.org/10.1080/14719037.2013.806578.

Baccini P. A city's metabolism: towards the sustainable development of urban systems. J Urban Technol. 1997;4(2):27-39. https://doi.org/10.1080/10630739708724555.

Barton $\mathrm{H}$, Grant M. Urban planning for healthy cities. A review of the progress of the European healthy cities Programme. J Urban Health Bull New York Acad Med, 90 Suppl. 2013;1(Suppl 1):129-41. https://doi.org/10.1007/s11524-011-9649-3.

Brandsen T, Pestoff V. Co-production, the third sector and the delivery of public services. Public Manag Rev. 2006;8(4):493501. https://doi.org/10.1080/14719030601022874.

Brundtland GH. Our common future; 1987. Retrieved from http://www.un-documents.net/our-common-future.pdf.

Bryson J, Sancino A, Benington J, Sørensen E. Towards a multi-actor theory of public value co-creation. Public Manag Rev. 2017;19(5):640-54. https://doi.org/10.1080/14719037.2016.1192164.

C4P Mobility Labs | Cities4People. (n.d.). Retrieved April 2, 2019, from https://cities4people.eu/c4p-mobility-labs/.

Cassia F, Magno F. Public services co-production: exploring the role of citizen orientation. Int J Qual Serv Sci. 2009;1(3):33443. https://doi.org/10.1108/17566690911004249.

Cities-4-People. (n.d.). Car free for six months: a bold move for Ottensen | Cities4People. Retrieved April 2, 2019, from https:// cities4people.eu/2019/04/01/car-free-for-six-months-a-bold-move-for-ottensen/.

Corsín Jiménez A. The right to infrastructure: a prototype for open source urbanism; 2014. https://doi.org/10.1068/d13077p.

Curley M, Salmelin B. Open innovation 2.0: a new paradigm. In: 2008 eighth international conference on hybrid intelligent systems; 2008. p. 959-60. https://doi.org/10.1109/HIS.2008.172.

de Leeuw E. Do healthy cities work? A logic of method for assessing impact and outcome of healthy cities. J Urban Health. 2012;89(2):217-31. https://doi.org/10.1007/s11524-011-9617-y.

Dijst M, Worrell E, Böcker L, Brunner P, Davoudi S, Geertman S, et al. Exploring urban metabolism—towards an interdisciplinary perspective. Resour Conserv Recycl. 2018;132:190-203. https://doi.org/10.1016/J.RESCONREC.2017.09.014.

Duhl, L. J., \& Sanchez, A. K. (n.d.). Regional office for Europe healthy cities and the city planning process a background document on links between health and urban planning. Retrieved from http://www.euro.who.int/_data/assets/pdf_file/ 0009/101610/E67843.pdf.

European Commission. GREEN PAPER:towards a new culture for urban mobility; 2007. Retrieved from https://eur-lex.europa. eu/legal-content/EN/TXT/PDF/?uri=CELEX:52007DC0551\&from=EN.

European Commission. The three essential steps to co-creation; 2016. Retrieved from https://ec.europa.eu/esf/ transnationality/content/three-essential-steps-co-creation.

Girardet H. Regenerative cities. Hamburg; 2010. Retrieved from https://www.worldfuturecouncil.org/wp-content/uploads/2 016/01/WFC_2010_Regenerative_Cities.pdf.

Grant M, Brown C, Caiaffa WT, Capon A, Corburn J, Coutts C, et al. Cities and health: an evolving global conversation. Cities Health. 2017;1(1):1-9. https://doi.org/10.1080/23748834.2017.1316025.

Hancock T, Duhl L. Promoting health in the urban context. Copenhagen: FADL Publishers; 1986.

Health Organization Regional Office for Europe, W. (2014). Healthy cities Promoting health and equity-evidence for local policy and practice Summary evaluation of Phase V of the WHO European Healthy Cities Network. Retrieved from http:// www.euro.who.int/en/publications/abstracts/healthy-cities.-promoting-health-and-equity-evidence-for-local-policy-andpractice--summary-evaluation-of-phase-v-of-the-who-european-healthy-cities-network.

Healthy Cities Vision. (2018). Retrieved July 19, 2018, from http://www.euro.who.int/en/health-topics/environment-and-health/ urban-health/who-european-healthy-cities-network/healthy-cities-vision.

Healthy Cities Vision. (2019). Retrieved from http://www.euro.who.int/en/health-topics/environment-and-health/urban-health/ who-european-healthy-cities-network/healthy-cities-vision.

Hillier B. The city as a socio-technical system: a spatial reformulation in the light of the levels problem and THE parallel problem. In: Spatial information theory; 2009. Retrieved from https://core.ac.uk/download/pdf/1687401.pdf.

Hine J, Mitchell F. Better for everyone? Travel experiences and transport exclusion. Urban Stud. 2001;38(2):319-32. https://doi. org/10.1080/00420980020018619.

Hristova D, Aiello LM, Quercia D. The new urban success: how culture pays. Front Physiol. 2018;6:27. https://doi.org/10.3389/ fphy.2018.00027.

Kennedy C, Cuddihy J, Engel-yan J. The changing metabolism of cities. J Ind Ecol. 2007;11(2):44.

Khan Z, Dambruch J, Peters-Anders J, Sackl A, Strasser A, Fröhlich P, et al. Developing knowledge-based citizen participation platform to support Smart City decision making: the Smarticipate case study. Information. 2017;8(2):47. https://doi.org/10. 3390/info8020047.

Maptionnaire. (n.d.). Retrieved from https://maptionnaire.com/.

Mersal Mahmoud A. The impact of built environment on human behaviors. Int J Environ Sci Sustain Dev. 2018;2(1):1-12. https://doi.org/10.21625/essd.v2i1.157.g69.

Mollenkopf H, Marcellini F, Ruoppila I, Széman Z, Tacken M. Enhancing mobility in later life-personal coping, environmental resources and technical support. In: Mollenkopf H, Marcellini F, Ruoppila I, Széman Z, Tacken M, editors. The out-of-home mobility of older adults in urban and rural regions of five European countries. Amsterdam: IOS press; 2005.

Nevens F, Frantzeskaki N, Gorissen L, Loorbach D. Urban transition labs: co-creating transformative action for sustainable cities. J Clean Prod. 2013;50:111-22. https://doi.org/10.1016/J.JCLEPRO.2012.12.001.

Puerari E, de Koning J, von Wirth T, Karré P, Mulder I, Loorbach D. Co-creation dynamics in urban living labs. Sustainability. 2018;10(6):1893. https://doi.org/10.3390/su10061893.

Rashed R. Urban agriculture: a regenerative urban development practice to decrease the ecological footprints of cities. Int J Environ Sci Sustain Dev. 2018;2(1):11. https://doi.org/10.21625/essd.v2i1.170.

Rogers DS, Duraiappah AK, Antons DC, Munoz P, Bai X, Fragkias M, et al. A vision for human well-being: transition to social sustainability. Curr Opin Environ Sustain. 2012;4(1):61-73. https://doi.org/10.1016/J.COSUST.2012.01.013. 
Rosenstein C. Cultural development and City neighborhoods; 2008. Retrieved from https:/www.urban.org/sites/default/files/ publication/30561/411937-Cultural-Development-and-City-Neighborhoods.PDF.

Siri JG. Sustainable, healthy cities: making the most of the urban transition. Public Health Rev. 2016;37:22. https://doi.org/10. 1186/s40985-016-0037-0.

Sorrentino M, Sicilia M, Howlett M. Understanding co-production as a new public governance tool. Polic Soc. 2018;37(3):27793. https://doi.org/10.1080/14494035.2018.1521676.

Späth P, Knieling J. How EU-funded Smart City experiments influence modes of planning for mobility: observations from Hamburg. Urban Transformations. 2020;2(1):2. https://doi.org/10.1186/s42854-020-0006-2.

Thomson G, Newman P. Cities and the Anthropocene: urban governance for the new era of regenerative cities. Urban Stud. 2018a;004209801877976. https://doi.org/10.1177/0042098018779769.

Thomson G, Newman P. Urban fabrics and urban metabolism - from sustainable to regenerative cities. Resour Conserv Recycl. 2018b;132:218-29. https://doi.org/10.1016/j.resconrec.2017.01.010.

UN-Habitat. Cities and climate change : policy directions : global report on human settlements, 2011; 2011. Earthscan. Retrieved from http://mirror.unhabitat.org/pmss/(X(1)S(5tvsvarhlmm04gszd2kwsd3m))/listltemDetails.aspx?publicationID= 3085\&AspxAutoDetectCookieSupport=1.

United Nations (UN). (2018). 68\% of the world population projected to live in urban areas by 2050, says UN | UN DESA | United Nations Department of Economic and Social Affairs. Retrieved April 3, 2019, from https://www.un.org/ development/desa/en/news/population/2018-revision-of-world-urbanization-prospects.html.

United Nations, Department of Economic and Social Affairs, P. D. World population prospects 2019:highlights (ST/ESA/SER.A/ 423); 2019. Retrieved from https://population.un.org/wpp/Publications/Files/WPP2019_Highlights.pdf.

van der Jagt APN, Smith M, Ambrose-Oji B, Konijnendijk CC, Giannico V, Haase D, et al. Co-creating urban green infrastructure connecting people and nature: a guiding framework and approach. J Environ Manage. 2019;233:757-67. https://doi.org/ 10.1016/J.JENVMAN.2018.09.083.

World Bank. Cities and climate change: an urban agenda; 2010. Retrieved from http://siteresources.worldbank.org/INTUWM/ Resources/340232-1205330656272/CitiesandClimateChange.pdf.

World Health Organization (WHO). Healthy cities vision; 2019. Retrieved April 3, 2019, from http:/www.euro.who.int/en health-topics/environment-and-health/urban-health/who-european-healthy-cities-network/healthy-cities-vision.

\section{Publisher's Note}

Springer Nature remains neutral with regard to jurisdictional claims in published maps and institutional affiliations.

\section{Ready to submit your research? Choose BMC and benefit from:}

- fast, convenient online submission

- thorough peer review by experienced researchers in your field

- rapid publication on acceptance

- support for research data, including large and complex data types

- gold Open Access which fosters wider collaboration and increased citations

- maximum visibility for your research: over $100 \mathrm{M}$ website views per year

At $\mathrm{BMC}$, research is always in progress.

Learn more biomedcentral.com/submissions 